\title{
Ethics: What is the Research Scenario in the Brazilian Symposium SBSI?
}

\author{
Luiz Paulo Carvalho ${ }^{1}$, José Antonio Suzano ${ }^{2}$, Jonice Oliveira ${ }^{1}$, Flávia Maria \\ Santoro $^{3}$ \\ ${ }^{1}$ Programa de Pós-Graduação em Informática (PPGI) - UFRJ \\ Rio de Janeiro, RJ - Brasil \\ ${ }^{2}$ Departamento de Matemática Aplicada (DMA) - UFRJ \\ Rio de Janeiro, RJ - Brasil \\ ${ }^{3}$ Departamento de Ciência da Computação (DCC) - UERJ \\ Rio de Janeiro, RJ - Brasil \\ luiz.paulo.carvalho@ppgi.ufrj.br, jose.suzano@matematica.ufrj.br, \\ joniceddcc.ufrj.br, flaviadime.uerj.br
}

\begin{abstract}
Is there an Ethical thinking in the development of Information Systems research and engineering in Brazil? The immanence of information systems is multidisciplinary and encompasses socio-technical plurality, unlike other areas of computing, such as computer science or engineering. When considering the epistemological breadth of the discipline, which starts from technique to the study of application, impact, influence and use; the importance of the domain of Ethics becomes paramount. How to think-do Information Systems without reasoning ethically about it? We conducted a Systematic Literature Review guided by the main research question: how does ethics permeate research published in the SBSI between 2011 and 2020? At the same time, how does this phenomenon relate to the Great Challenges in Information Systems (2016-2026)? less than $10 \%$ of the more than 700 articles published deal with some ethical aspect, superficially; and less than $1 \%$ with ownership. The Ethics Committee was reported in only one article, with very few occurrences of informed consent. That is, SBSI finds itself in a scenario of deep scarcity and shallowness in this topic.
\end{abstract}

\section{Introduction}

Information Systems (IS) is an area, in the range of the academic-scientific computing environment, which is socioculturally undervalued. This qualification was already noticed since the 20th century [Cohen 1999], with some negative value judgments about its transdisciplinary essence. The area would be lacking its own tradition and focus, or its own theories. One of the supposed demerits deals with his shift to non-positivist, non-deterministic, non-objective, or non-technicist sciences; i.e., moving away from the conservatism and traditionalism of the scientific "elite", the so-called "hard sciences" and approaching areas considered "non-hard sciences", such as Anthropology; Sociology; 
Psychology; Race, Gender or Sexuality Studies; Management Studies; Economy; Communication Studies; among others. And as [Cohen 1999, Kohun et al. 2012] points out, this epistemic richness is actually one of its advantages.

Despite this discrimination, IS is well-established in Brazil. The Brazilian IS community organizes its own communication event dedicated to the theme, the Brazilian Symposium on Information Systems (Simpósio Brasileiro de Sistemas de Informação SBSI), for academic-scientific fraternization and debate. Given its plural nature, SBSI also organizes tracks for industry and innovation, and is the largest event dedicated to IS research, teaching and innovation in Brazil.

In 2021 the SBSI held its seventeenth edition, indicating the well-established maturity of the community and the field. In 2016, a seminar was held with the objective of deliberating, establishing and documenting major challenges for the area in Brazil, between the years 2016 and 2026. Published as Great Challenges for Information Systems (Grandes Desafios de Sistemas de Informação - GranDSI-BR) [Boscarioli et al. 2017].

An intrinsic and inseparable theme to IS is Ethics [Laudon e Laudon 2020, Stair e Reynolds 2018]. When applied to Computing it is known as Computational Ethics [Barger 2008]. However, this is an open debate, considering that the Computing subareas present significant differences, for example, Computer Engineering and Computer Science degrees. In this sense, we can think of Ethics applied to decision making in Information Systems [Carvalho et al. 2021]. This ethical reason permeates research as well as operational engineering and innovation.

Briefly, Ethics studies human actions and practices [Fieser 2021]. Considering the high amount of research in IS in Brazil dedicated to the production of artifacts [Araujo et al. 2017], it is worth emphasizing that ethical analysis extends to idealized, designed and implemented artifacts. Technological artifacts carry the values, or lack thereof, of everyone actively involved in the development stages [Pereira et al. 2015].

In this work, we conduct a Systematic Literature Review (SLR) on the occurrence of ethical aspects through SBSI academic-scientific production from 2011 to 2020 . We will cover the full and short papers published in the main research track. Simultaneously, we will analyze the relationship of the Computational Ethics theme with the GranDSI-BR, is there an occurrence of this topic in the document? And if so, how do they occur?

In the Portal de Periódicos $C A P E S^{1}$ repository, which indexes several databases of scientific publications, there is no concurrent SLR result for the "ethics information systems literature review" string search, both in English and in Brazilian Portuguese. External to this search, we raised four competing SLRs covering the Ethics and Information Systems themes [Bock et al. 2021, Paradice et al. 2018, Stahl 2012, Mingers e Walsham 2010]. These SLRs are comprehensive to the domain as a whole, and a differential of this present work is to depicts a portion of the research panorama in Ethics and IS in Brazil, empirically. That is, what is being concretely and effectively produced and published. We adopted an approach similar to [Silva et al. 2018], which conducts an SLR on Privacy and its relation to the scientific production of the IHC-Br symposium.

\footnotetext{
${ }^{1}$ https://www-periodicos-capes-gov-br.ezl.periodicos.capes.gov.br/. Accessed 06/06/2021
} 
In 2012, [Adam 2012] points out: "Looking back over the last 15 or so years it is clear that, whatever turns IS did make, the ethical turn was not one of them". In this same direction, has the Brazilian IS community considered ethical aspects after 2012? Are they relevant enough to feature in the GrandDSI-BR and SBSI scientific production? Or, even after 2012, is it still the same as Adam's previous perception?

In Section 2 the research methodology and method are explained; Section 3 covers the GrandDSI-BR and the SLR, main contribution of this paper; Section 4 closes with discussion and conclusion.

\section{Research methodology and method}

The guidelines proposed by [Kitchenham 2004, Kitchenham e Charters 2007] were chosen for the purpose of identifying and interpreting the panorama regarding a topic of interest. We used guidelines to collect, select, and summarize relevant research, in a way to ensure the replicability of the process, through this well-known guideline. Google Sheets was used to support data management, through a shared spreadsheet. The primary objective of this research is to present a panorama of ethical aspects through scientific communications categorized as full or short papers published in the SBSI event between 2011 and 2020. 2011-2017, papers hosted by Sociedade Brasileira de Computação (SBC); 2018-2020, by the Association of Computing Machinery (ACM).

We divided the question linked to the primary objective into subsequent research questions (RQ), due to space limitations we will announce each one accompanied by its answer in Section 3. In line with the SLR objective, we focus on the explicit occurrence of terms associated with ethical aspects. For example, if a publication deals with virtuously design practices without explicitly citing ethics or morals, it is outside our scope.

Morphological constructions are considered, for ethics we searched for "ethic", such as ethics or ethical; for Brazilian Portuguese "etic", as eticamente, ética, ético; and for morals we look for "moral", namesake in English or Brazilian Portuguese, like moralmente or morally. Considering the plural, "morais". We also consider Ethics Committee (Comitê de Ética - EC) and Informed Consent (Consentimento Esclarecido - IC).

The data extraction process is the step where we extract relevant data and information [Kitchenham e Charters 2007]. The results can be: open question, means that answers depend on what comes up, if it does, in the content; interpretative question are based on quality criteria defined and consensually accepted by all the authors; closed question, answers are predetermined, such as methodological approach. In case it was impossible to extract or infer information objectively, we indicate accordingly, e.g., paper does not present the scientific approach and the inference of this data is compromised.

We conducted two stages, a wide and a narrow screening. In the first stage, two independent researchers conducted the initial extraction through the search for terms: one performed the extraction and the other reviewed the results. The papers were qualified for their relevance and adherence to the Ethics context. Those considered adherent were chosen for the second step. Adherent papers delve into the ethical or moral analysis, regardless of the amount of occurrence of related terms. It is not about how much the term is repeated, but the quality of its occurrence and its relationship with the SLR objective.

Figure 1 depicts the selection process and results. The wide screening resulted 
(1)



\begin{tabular}{|l|l|}
\hline $2011=34$ & $2012=77$ \\
\hline
\end{tabular}

$2013=802014=63$

\begin{tabular}{|l|l|}
$2015=100$ & $2016=80$ \\
\hline $2017=79$ & $2018=71$ \\
\hline
\end{tabular}

\begin{tabular}{l|l|l|}
$2017=79$ & $2018=71$ \\
\hline $2019=76$ & $2020=47$ \\
\hline
\end{tabular}

\begin{tabular}{ll|l}
$2019=76$ & $2020=47$ \\
\hline
\end{tabular}
(2)

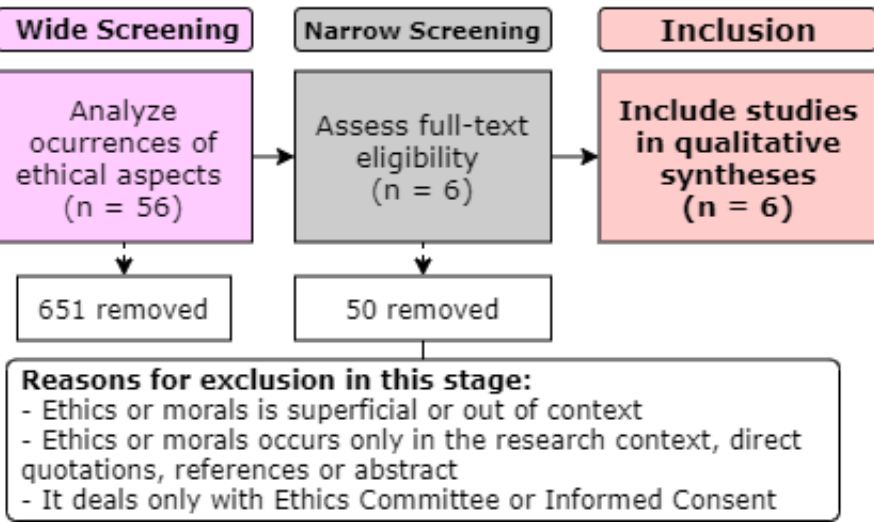

Figure 1. Diagram of the literature review process.

in 56 papers; the narrow screening, 6 papers. The quantitative and comprehensive analysis involved the wide and narrow screening papers; the in-depth qualitative synthesis involved narrow screening papers. With these analyses, we richly expose the panorama. For auditability and reproducibility, the online database with results from the wide and narrow screening is available online ${ }^{2}$.

\section{A lost decade of SBSI and Ethics, 2011 - 2020}

Initially we will deal with the GranDSI-BR [Boscarioli et al. 2017], the document was deliberated and elaborated in 2016 during an SBSI, in a seminar. Despite claiming to be dedicated to Brazil and the Brazilian context, it is only available in English. There are 21 occurrences of the term ethics and variations, there is no challenge directly and primarily directed to Ethics. Only one of the thirteen challenges at first glance addresses the topic, "Systemic and Socially Aware Perspective for Information Systems", arguing that technical, social, legal and ethical problems in the development and use of information systems arise from a narrow understanding of IS that do not favor the social world in which they exist and are used. The topic of Ethics is far from relevant as associated with the challenges perceived by the community between the decade $2016-2026$.

Table 1. Data extraction numerical results

\begin{tabular}{|c|c|c|c|c|c|c|c|c|c|c|c|c|}
\hline Year & 2011 & 2012 & 2013 & 2014 & 2015 & 2016 & 2017 & 2018 & 2019 & 2020 & $\mathbf{T}$ & T\% \\
\hline Total (T) & 34 & 77 & 80 & 63 & 100 & 80 & 79 & 71 & 76 & 47 & 707 & $100,00 \%$ \\
\hline EC & 0 & 0 & 0 & 0 & 1 & 0 & 0 & 0 & 0 & 0 & 1 & $0,14 \%$ \\
\hline IC & 0 & 1 & 1 & 1 & 2 & 2 & 2 & 1 & 1 & 7 & 18 & $2,55 \%$ \\
\hline EC+IC & 0 & 0 & 0 & 0 & 0 & 0 & 0 & 0 & 0 & 0 & 0 & $0,00 \%$ \\
\hline Not adhere & 1 & 2 & 4 & 2 & 9 & 10 & 6 & 4 & 2 & 10 & 50 & $7,07 \%$ \\
\hline Adhere & 0 & 1 & 0 & 0 & 1 & 1 & 0 & 2 & 0 & 1 & 6 & $0,85 \%$ \\
\hline Adhere or not & 1 & 3 & 4 & 2 & 10 & 11 & 6 & 6 & 2 & 11 & 56 & $7,90 \%$ \\
\hline Not adhere & $2,90 \%$ & $2,60 \%$ & $5,00 \%$ & $3,20 \%$ & $9,00 \%$ & $12,50 \%$ & $7,60 \%$ & $5,60 \%$ & $2,60 \%$ & $21,30 \%$ & & \\
\hline Adhere & $0,00 \%$ & $1,30 \%$ & $0,00 \%$ & $0,00 \%$ & $1,00 \%$ & $1,30 \%$ & $0,00 \%$ & $2,80 \%$ & $0,00 \%$ & $2,10 \%$ & & \\
\hline Adhere or not & $2,90 \%$ & $3,90 \%$ & $5,00 \%$ & $3,20 \%$ & $10,00 \%$ & $13,80 \%$ & $7,60 \%$ & $8,50 \%$ & $2,60 \%$ & $23,40 \%$ & & \\
\hline
\end{tabular}

About the scientific production in the SBSI main research track, the general results are presented in Table 1 and Figure 2. A total of 707 papers were analyzed. Only 56 (less

\footnotetext{
${ }^{2}$ https://cutt.ly/lnNa7XJ. Accessed 06/06/2021
} 

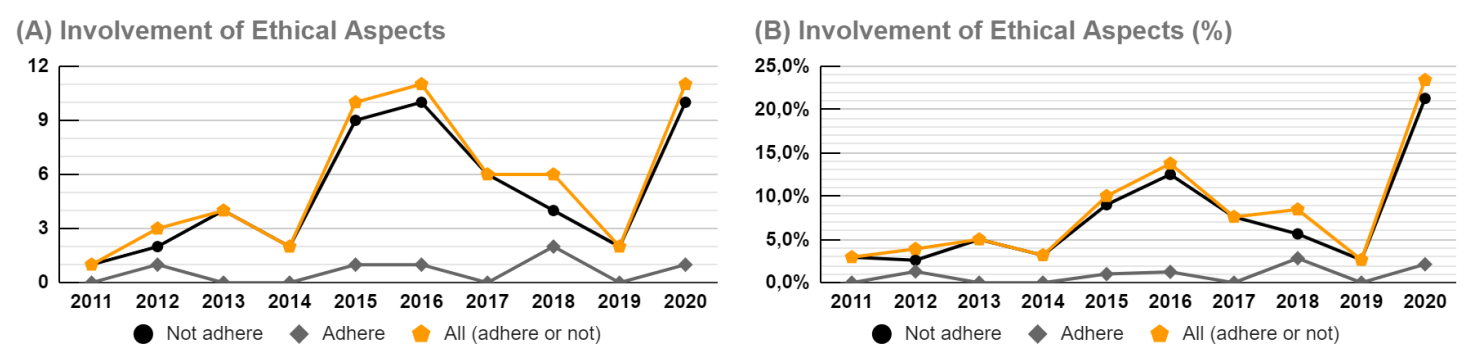

Figure 2. Results chart, absolute (A) and proportional (B).

than 10\%) mentioned EC, IC or terms associated with Ethics or Moral. Only one article, and respective research, indicated EC involvement. No paper indicated joint involvement of IC and EC, i.e., appreciation by an Ethics Committee + Informed Consent.

The occurrence, in quantity and proportion, of IC compared to the amount of research involving human participants is categorically discrepant. In 2015, 100 papers were approved and published and only two indicated IC, considering whether this consent was formally acquired, through a term, or informally, tacitly requested.

Of the papers that went beyond the strict relationship with IC/EC, 37 mentioned the terms ethics or morals, and variations. They are superficial or brief quotes, without specificity that allows further analysis, e.g., "This way, it was also possible to have a vision of the emotional and ethical perspective in relation to the tool" [Petry et al. 2016] [authors' translation]. Which ethical perspective? There is no way to know.

The four authors of this study analyzed the 37 papers. We reached the consensus that 6 of them present the ethical aspects appropriately and in depth [Madeo et al. 2012, Wang e Prado 2015, Prado e Wang 2016, Oliveira et al. 2018, Camargo et al. 2018, Oliveira et al. 2020]. They were classified, then reviewed by another researcher and then a consensus was reached on the papers to be considered for qualitative synthesis. In [Oliveira et al. 2018, Camargo et al. 2018] there was only one occurrence of the terms, in each of the other four there were 9 or more.

About RQ1, technological domain, four of them dealt with distinct technological domains and two without specific ones. For example, [Madeo et al. 2012] deals with High Frequency Trading and [Camargo et al. 2018] with Distributed Denial of Service. As RQ2, ethics episteme, all six papers deal with application as an ethical aspect. None of them discuss the ethical aspects related to the research being carried out. There are only vague notes, e.g., respecting the privacy of the participants by anonymizing their names.

As RQ3, relationship with human participants, only [Prado e Wang 2016, Oliveira et al. 2018] involved participants in the related research. Even if they needed to, neither of the two papers mentions IC/EC. The other four papers did not involve human participants, therefore, they do not require the involvement of IC/EC [Brasil 2016]. To identify which institutions are most involved with the topic, RQ4 deals with institutions involved. We analyze the ones that appear at least once related to authorship. USP is the most recurrent, present in four of the six papers. UNIFEI, UFLA and UFU have one occurrence each.

Through methodological analysis, RQ5 synthesizes the methodological ap- 
proaches. There was a complication, as many of them ignore the methodological approach statement. There is no way to know if it is a quantitative, qualitative research or whatever, because some of the works, in addition to ignoring the statement of approach, also leave out the statement of methodology and research methods. Thus, it was impossible for us to present this synthesis accurately. On the other hand, this should be an essential fact to be shown in a scientific communication.

RQ6 and RQ7, respectively, deal with ethical principles and challenges and difficulties. The domain of Ethics is equipped with its own principles, foundations and bases; for example, utilitarianism, deontology, consequentialism, realism, idealism, among others [Fieser 2021]. None of the six papers presented any formal ethical basis, neither brief nor simplistic. Just as none presented any challenge or difficulty linked to Ethics, primarily or secondarily. Regarding the legislation, [Oliveira et al. 2020] says: "Those issues show how urgent it is to incorporate more effective policies to promote accessibility in a range of technological approaches to providing digital government services to citizens, be it on mobile devices , websites or other media.", which is implicitly an ethical concern.

Finally, after a detailed scan of these six papers, we found contradictions and inconsistencies in some discursive conducts. For example, in [Madeo et al. 2012] we find both "This type of system brought great benefits to the market [...]" and "Several authors believe that these systems are harmful to the market, as they allow practices unethical and even illegal" [authors' translation]. In several passages there is a clash of ideas, with arguments without citations. For example, who are "several authors"? And if the system is harmful and allows for unethical and illegal actions, how is it beneficial?

The same occurs explicitly in [Oliveira et al. 2020], where we find "[...] some agencies also showed that moral obligation to disabled people appeared to be an important aspect in some agencies that reported to request accessibility requirements and evaluations with users in their systems" and also "[...] governmental agencies seem to use the lack of precision in some laws to bypass legal obligations [...]" [authors' translation]. These two passages contradict each other, and if they occur in different agencies, why did not the authors explain accordingly? For these are relevant ethical assessments.

In [Oliveira et al. 2018] the excerpt that discusses ethical aspects associated with privacy presents ethically dubious conjectures, e.g., "[...] probably because he is a teenager and does not understand the complexity factors involved in the security and privacy issue [...]" [authors' translation]. This is an unethical inference from the participant's interaction, as it disrespects their spontaneous and legitimate answer and cognition. There is no reference supporting the prejudicial claim that "teenagers are alienated from security and privacy factors," and the respective research is not focused on estimating these factors. When the participant, who is an adolescent, expresses a response that is different from the one expected by the authors' analysis, it is belittled.

\section{Discussion and conclusion}

In this paper, we present an SLR to expose the panorama of ethical aspects in IS research published in the SBSI main research track that took place in the decade between 2011 2020. Regarding the GranDSI-BR, both the relevance of ethical aspects is minimal, nor did it directly influence further research on this topic.

Based on the results raised here, we reverberate the criticism of [Adam 2012], the 
ethical shift has not arrived and seems to be far from the IS research published in the SBSI. This is also true for secondary ethical criteria, such as IC and EC, which are neglected. There is a chasm of ethical deficiency in the SBSI, where only $2.55 \%$ of papers explicitly indicate the acquisition of consent; less than $1 \%$ delve into ethical aspects; and in none of the years the proportional amount of papers involving any ethical aspects exceeded $25 \%$, being the largest in 2020 with $23.4 \%$.

In this sense, this present work brings two positions. First, to expose the arid scenario and call the community to greater ethical awareness in its practices and research, a conscious and mature community reflects on its issues, and the Brazilian community, mainly through its socially strong nodes and organizers, such as event committees, can influence this change. The second is not a call for ethics bashing or an ethical "inquisitorial crusade" in Brazilian IS, however filling in some gaps is the least expected, such as rigorously dealing with the topic of IC/EC.

As future works, cover other communications and events dedicated to IS; produce guides and frameworks that help the Brazilian community to advance the Ethics agenda; and follow the evolution of the scenario over time, critically.

\section{References}

Adam, A. (2012). IS and its agenda. Journal of Inf. Tec., 27(2):102-103.

Araujo, R., Fornazin, M., and Pimentel, M. (2017). An analysis of the production of scientific knowledge in research published in the first 10 years of isys (2008-2017). iSys - Brazilian Journal of Information Systems, 10(4):45-65.

Barger, R. (2008). Computer Ethics: A Case-Based Approach. Cambridge University Press, Cambridge, RU.

Bock, A., España, S., Gulden, J., Jahn, K., Nweke, L. O., and Richter, A. (2021). The ethics of information systems: The present state of the discussion and avenues for future work. Number 51 in ECIS 2021 Research-in-Progress Papers.

Boscarioli, C., Araujo, R., and Suzana, R. (2017). I GranDSI-BR Grand Research Challenges in Information Systems in Brazil 2016-2026. SBC, Porto Alegre.

Brasil (2016). RESOLUÇÃO N 510, DE 7 DE ABRIL DE 2016. Accessed in 06/06/2021 in: http://bit.ly/2fmnKeD.

Camargo, C. O., Faria, E. R., Zarpelão, B. B., and Miani, R. S. (2018). Avaliação sobre a qualidade de conjuntos de dados associados a ataques de negação de serviço. In Anais do XIV SBSI, Porto Alegre, RS, Brasil. SBC.

Carvalho, L. P., Oliveira, J., and Santoro, F. (2021). Uma análise exploratória de práticas associadas à Ética computacional através do ciberespaço brasileiro. In Anais do II WICS, Porto Alegre, RS, Brasil. SBC.

Cohen, E. (1999). Reconceptualizing information systems as a field of the transdiscipline informing science: From ugly duckling to swan. Journal of Comp. and Inf. Tec., 7(23).

Fieser, J. (2021). Ethics. In The Internet encyclopedia of philosophy. https://iep.utm.edu/ethics/. Accessed in: 06/06/2021. 
Kitchenham, B. (2004). Procedures for performing systematic reviews. Keele, UK, Keele Univ., 33.

Kitchenham, B. and Charters, S. (2007). Guidelines for performing systematic literature reviews in software engineering. Technical Report EBSE 2007-001, Keele University and University of Durham.

Kohun, F., Rodi, A. F., and Delorenzo, G. (2012). Does Information Systems Suffer an Identity Crisis? A Case Study of Confusion and Misinformation. IIS, 13(2):328-335.

Laudon, K. and Laudon, J. (2020). Management Information Systems: Managing the Digital Firm. Pearson, Nova Iorque, NI, 16th edition.

Madeo, R., Ramalho, N., Ferreira, F., and Fantinato, M. (2012). Sistemas de informação no mercado de ações: Papel estratégico e impactos Éticos, sociais e políticos. In Anais do VIII SBSI, Porto Alegre, RS, Brasil. SBC.

Mingers, J. and Walsham, G. (2010). Toward ethical information systems: The contribution of discourse ethics. MISQ., 34(4):833-854.

Oliveira, A., da Silva, L., Eler, M., and Freire, A. (2020). Do brazilian federal agencies specify accessibility requirements for the development of their mobile apps? In Anais do XVI SBSI, Porto Alegre, RS, Brasil. SBC.

Oliveira, M., Mattedi, A. P., and Seabra, R. D. (2018). Percepções sociais sobre a adoção de aplicativos para smartphones no contexto da segurança pessoal. In Anais do XIV SBSI, Porto Alegre, RS, Brasil. SBC.

Paradice, D., Freeman, D., Hao, J., Lee, J., and (2018), D. H. (2018). A review of ethical issue considerations in the information systems research literature. Foundations and Trends R in Information Systems: Vol. 2, 2(2):117-236.

Pereira, R., Baranauskas, M. C. C., and Liu, K. (2015). The value of values for hci: An informed discussion beyond philosophy. In Anais do XIV IHC, IHC '15, New York, NY, USA. Association for Computing Machinery.

Petry, M., Barbosa, J., Rigo, S., and Horta, R. (2016). Hígia: Um modelo para cuidado ubíquo de pessoas com depressão. In Anais do XII SBSI, Porto Alegre, RS, Brasil. SBC.

Prado, E. and Wang, M. (2016). Um estudo exploratório sobre a alfabetização computacional em são paulo. In Anais do XII SBSI, Porto Alegre, RS, Brasil. SBC.

Silva, E., Torres, B., Sacramento, C., Capra, E. P., Ferreira, S. B. L., and Garcia, A. C. B. (2018). Privacy: What is the Research Scenario in Brazilian Symposium IHC? In Anais do XVII IHC, IHC 2018, New York, NY, USA. Association for Computing Machinery.

Stahl, B. C. (2012). Morality, ethics, and reflection: A categorization of normative is research. JAIS, 13(8):636-656.

Stair, R. M. and Reynolds, G. W. (2018). Principles of Information Systems. CENGAGE Learning, Boston, MA, 13th edition.

Wang, M. and Prado, E. (2015). Revisão sistemática sobre alfabetização computacional. In Anais do XI SBSI, Porto Alegre, RS, Brasil. SBC. 